\title{
Time Dependent Factors Affecting the Duration of Work Disability after Compensated Low-back Pain in South Korea
}

\author{
Ji-Yun KIM"1, Kyung Ja JUNE²*, Bong-Min YANG ${ }^{3}$, \\ Eunok PARK ${ }^{4}$ and Kyung Min PARK ${ }^{5}$
}

\author{
${ }^{1}$ Department of Nursing, Cheju Halla College, South Korea \\ ${ }^{2}$ Department of Nursing, Soonchunhyang University, 366-1 Ssanyong-dong, Choanan-si, 330-090 South Korea \\ ${ }^{3}$ School of Public Health, Seoul National University, South Korea \\ ${ }^{4}$ Department of Nursing, Cheju National University, South Korea \\ ${ }^{5}$ College of Nursing, Keimyung University, South Korea
}

Received October 8, 2004 and accepted February 17, 2006

\begin{abstract}
The purpose of this study was to investigate the time dependent effects among factors affecting duration of work disability after compensated low-back pain. A postal survey involving 238 compensated workers at 39 companies was performed between January 5, 2004, and March 23, 2004. Cox proportional hazard regression analysis was used to model the effect of demographic, work-related, and injury factors affecting the duration of work disability. The variables that significantly affected the duration of work disability were age, company size, compensation benefit, pain radiation, and diagnosis. In addition, company size and pain radiation showed statistically significant time dependent effect. Consequently, this study found that there were time dependent factors affecting the duration of work disability. A phase-specific analysis would be useful to make policy for the prevention of long term disability after back injury.
\end{abstract}

Keywords: Compensated low-back pain, Duration of work disability, Phase-specific analysis

\section{Introduction}

Compensated low-back pain (LBP) is a matter of particular importance, since this is the leading cause of disability for workers under the age of $45 \mathrm{yr}^{1)}$ and the second leading cause of industrial absenteeism ${ }^{2}$ in the U.S. While most people with occupational LBP recover quickly ${ }^{3)}, 5-10 \%$ of patients with long-term or permanent disability resulting from LBP account for $70 \%$ to $90 \%$ of all costs that result from $\mathrm{LBP}^{4,5}$.

The duration of work disability needs to be conceptualized as a developmental phenomenon that is influenced by the various predicting factors acting at different time after the onset of symptoms ${ }^{4,6-8)}$. Because of these time-dependent

*To whom correspondence should be addressed. influences, the investigation of prognostic risk factors requires several stages or phases to be considered in the development of long-term work disability ${ }^{4,7-9)}$. Previous studies reported there was a significant difference among predicting factors between acute and subacute/chronic phase ${ }^{10,11)}$ of work disability. The phase specific factors identified in these studies were injury-related variables such as injury severity and previous back injury, and work-related factors such as job strain, work-schedule flexibility, and job control ${ }^{10,11}$.

It is well known that the disability length of compensated LBP is exceptionally long in South Korea. Incidence rate of work-related LBP was $81-113$ per 100,000 workers per year and it was $14-17 \%$ of total compensated cases in $1997^{12}$. Average compensated treatment period of total work-related LBP was $253 \mathrm{~d}$ in $1997^{12)}$ and that of herniated intervertebral 
disc disorder (HIVD) was $538 \mathrm{~d}$ in large shipbuilding companies from 1997 to $2002^{13)}$. The cases with $1-2 \mathrm{yr}$ disability were $20 \%{ }^{12}$. To reduce long-term LBP disability cases and to promote the return to work rate, it is needed to investigate which factors are differently affecting on the duration of work disability in early phase and chronic phase after back injury.

The purpose of this study is to identify the time dependent predictors on the duration of work disability after compensated back injury.

\section{Materials and Methods}

\section{Subjects}

The subjects of this study were compensated for LBP between January 1, 2000 and December 31, 2003, and worked in 39 manufacturing companies with a high incidence of musculoskeletal injury in 10 provinces among total 16 provinces. In South Korea, occupational low back pain is certified based on the Industrial Accident Compensation Insurance Act. According to this act, workers, who have low back pain caused by their duties and needed medical care for more than four days, can submit the application form for workers compensation to the Korea Labor Welfare Corporation. This application form should be confirmed by their employers and medical doctors, and the Korea Labor Welfare Corporation will announce the acceptance to the worker, employer and health care institution through the internal review process.

Before the data collection, subjects were informed about the study by telephone, and 367 of the 441 eligible workers agreed to participate. Self-administered questionnaires were sent via the postal service and 292 questionnaires were returned, of which 47 cases were excluded for either insufficient information $(n=37)$ or misclassification of the date of the low-back injury $(n=10)$. All subjects were recruited between January 5, 2004, and March 23, 2004.

To reduce the selection bias problem, we confirmed that there was no significant difference in the duration of work disability between participants and non-participants of our study ( $\mathrm{t}=-0.76, \mathrm{P}=0.46)$. In one company, we had the wage information. The analysis result was that there was no significant difference in the wage between participant and non-participant in our study $(\mathrm{t}=1.06, \mathrm{P}=0.86)$.

\section{Measurements}

Variables identified as prognostic factors for duration of work disability and included in the analyses were age, sex, marital status, company size, length of pre-injury employment, union membership, financial compensation, pain radiation, and diagnosis, as explained in previous duration of disability studies ${ }^{10,14-18}$. Company size, length of pre-injury employment, and compensation benefit were each categorized into two levels based on the total number of employees, the total year of employment, and the monthly compensation rate, respectively. Pain radiation was determined by whether or not the workers had symptoms at entry to the back injury. Workers with symptoms complained that the pain radiated in each leg to the buttock, knee, heel, or toe.

For diagnosis, we categorized workers into two groups on the basis of the medical diagnosis at the time when they were accepted as the compensation cases from the Korea Labor Welfare Corporation.

The outcome measure for the analysis is duration of work disability, of which the operational definition was the total number of compensated workdays calculated from the injury date to the final day of compensated medical treatment.

\section{Statistical analysis}

Cox proportional hazard regression analysis was used to model the effect of each independent variable affecting the duration of work disability. This analysis uses the duration of work disability presented by the first missed work-time episode following injury as the "survival" time. The regression coefficients provide estimates of the relative hazards for the various levels of each covariate, relative to the reference level. The relative hazard compares the hazard function for each study subgroup having a particular covariate pattern to that for the reference subgroup with a specified covariate pattern. Since we measured the duration of work disability, relative hazards greater than one indicate a shorter duration of work disability than in the reference group because hazard functions for the comparison and reference groups, whose ratio defines the relative hazard, refer to the instantaneous probability of shortening of duration of work disability.

Survival analysis techniques were also used to model the effects on the duration of work disability during two phases of the recovery process: (1) within the first 6 months of disability (pre-chronic phase) and (2) beyond the first 6 months of disability (chronic phase). Most phase studies in the literature have analyzed variables between the acute and subacute phases, with cutoff durations of 3-4 $\mathrm{wk}^{10)}, 7 \mathrm{wk}^{8,9)}$, and $8 \mathrm{wk}^{14}$. The second cutoff-between the subacute and chronic phases-has previously been set at 6 months ${ }^{8,9)}$ and 3 months ${ }^{19}$. In this study the cutoff between the pre-chronic and chronic phases was set at 6 months because the length 
of disability is unusually long in South Korea.

The differences between the relative hazard ratios in the pre-chronic and chronic phases were tested by entering each factor and its time-dependent covariates (variable times phase) into the same model.

As a first step in the analysis, the effect of each predictor affecting duration of work disability was investigated through the univariate analysis whilst separating the pre-chronic and chronic phases. For the pre-chronic phase, the disability experience of all 238 workers was included in the analyses. Workers who had more than 6 compensated months were censored at 6 month so as not to include their chronic phase experience when determining the influence of the variable during the pre-chronic phase. Only the 167 workers whose disability duration exceeded 6 months were included in models of the effect of each variable during the chronic phase.

As a second step, we tested the difference between the pre-chronic and chronic phase hazard ratios of each variable and its time-dependent covariate (variable times phase) into the same Cox model, where phase equaled 0 for the prechronic phase and 1 for the chronic phase. This allowed the effect of the predictors to change over the follow-up period. A significant value for the time-dependent covariate indicates that the phase-specific hazard ratios differ significantly from each other. As a third step, for variables showing phase-specific effects in the univariate analysis, we included their phase-specific terms in a single multivariate model. In the analysis, we used SAS system 8.1 version.

\section{Results}

Table 1 lists the descriptive statistics for the predictor variables. The mean age was $38.5 \mathrm{yr}$, and almost all the workers were male (97\%). Most of the workers (85\%) were living as a couple and had been working in companies with more than 1,000 employees. Half of the workers had been working for more than $10 \mathrm{yr}$, and about $91 \%$ were unionized. About a half of the workers received compensation benefit of at least 2,000,000 KRW(South Korean Won, thereafter KRW). The majority of workers (83\%) had LBP radiation, and a third of the medical diagnosis was categorized as a sprain $(33 \%)$.

The Cox univariate relative hazard ratios and the $95 \%$ confidence intervals (CIs) for each predictor are presented for the pre-chronic and chronic phases. We also provide the probability values from testing the difference in the hazard ratios between the two phases. Substantial and statistically significant phase-dependent effects were seen for two variables: company size and pain radiation. Workers in the companies
Table 1. Demographic, work-related and injury characteristics of the study sample $(n=238)$

\begin{tabular}{lc}
\hline Variable & $\mathrm{N}(\%)$ or M $\pm \mathrm{SD}$ \\
\hline Demographic variables & \\
Age (yr) & $38.48 \pm 6.66$ \\
Sex & $231(97.1)$ \\
$\quad$ Male & $7(2.9)$ \\
$\quad$ Female & \\
Marital status & $36(15.1)$ \\
$\quad$ Single, widow(er), or divorced & $202(84.9)$ \\
$\quad$ Living as a couple & \\
Work-related variables & \\
Company size & $38(16.0)$ \\
$\quad<1,000$ employees & $200(84.0)$ \\
$\quad \geq 1,000$ employees & \\
Length of preinjury employment & $121(50.8)$ \\
$\quad<10$ yr & $117(49.2)$ \\
$\geq 10$ yr & \\
Union membership & $216(90.8)$ \\
$\quad$ Yes & $22(9.3)$ \\
$\quad$ No & \\
Compensation benefit & $102(42.9)$ \\
$<2,000,000$ KRW/month & $136(57.1)$ \\
$\geq 2,000,000$ KRW/month & \\
Injury variables & \\
Pain radiation & \\
$\quad$ Yes & \\
No & \\
Medical diagnosis & \\
$\quad$ Sprain & \\
\hline
\end{tabular}

KRW: Korean Won (1 U.S\$ is equal to about 1,050 KRW in 2005.)

with less than 1,000 employees showed about 6 times more chance of recovery during the pre-chronic phase. However, this effect was very weak and became insignificant after 6 months of disability. The status without radiating pain showed a significant effect during the pre-chronic phase, but it did not show a significant effect during the chronic phase.

A predictor with significant effect for both phases was medical diagnosis, and the HIVD cases showed less chance of recovery than sprain cases.

The workers who were not union members were 3.72 times more likely to shorter the duration of disability than union members in pre-chronic phase.

Age, sex, marital status, length of pre-injury employment and compensation benefit did not show statistically significant effect on the duration of disability in both phases.

Table 3 lists the results of the Cox regression analysis when all of the predictors were entered into a single model. As we could confirm the company size and pain radiation 
Table 2. Univariate hazard ratios and $\mathbf{9 5 \%}$ CIs for demographic, work-related, \& injury variables between pre-chronic and chronic phase $(n=238)$

\begin{tabular}{|c|c|c|c|c|c|c|c|}
\hline Variable & $\begin{array}{l}\text { Pre-chronic } \\
\text { Hazard ratio }\end{array}$ & $\begin{array}{c}\text { phase } \\
95 \% \mathrm{CI}\end{array}$ & $P$ & $\begin{array}{c}\text { Chronic phase } \\
\text { Hazard ratio }\end{array}$ & $95 \% \mathrm{CI}$ & $P$ & $\begin{array}{c}\text { Phase } \\
\text { difference }(P)\end{array}$ \\
\hline \multicolumn{8}{|l|}{ Demographic variables } \\
\hline Age & 0.97 & $0.92-1.02$ & 0.27 & 0.97 & $0.93-1.00$ & 0.11 & 0.63 \\
\hline Sex Male & 1.00 & & & 1.00 & & & \\
\hline Female & 0.89 & $0.12-6.49$ & 0.90 & 0.45 & $0.06-3.26$ & 0.43 & 0.64 \\
\hline \multicolumn{8}{|l|}{ Marital status } \\
\hline Single, widow(er), or divorced & 1.00 & & & 1.00 & & & \\
\hline Living as a couple & 0.82 & $0.34-1.98$ & 0.66 & 1.32 & $0.68-2.57$ & 0.41 & 0.26 \\
\hline \multicolumn{8}{|l|}{$\begin{array}{l}\text { Work-related variables } \\
\text { Company size }\end{array}$} \\
\hline$<1,000$ employees & 6.39 & $3.25-12.57$ & $<.0001$ & 1.59 & $0.76-3.30$ & 0.22 & 0.00 \\
\hline$\geq 1,000$ employees & 1.00 & & & 1.00 & & & \\
\hline \multicolumn{8}{|l|}{ Length of pre-injury employment } \\
\hline$<10 \mathrm{yr}$ & 1.00 & & & 1.00 & & & \\
\hline$\geq 10 \mathrm{yr}$ & 1.36 & $0.69-2.69$ & 0.38 & 1.02 & $0.67-1.55$ & 0.94 & 0.62 \\
\hline \multicolumn{8}{|l|}{ Union membership } \\
\hline Yes & 1.00 & & & 1.00 & & & \\
\hline No & 3.72 & $1.68-8.24$ & 0.00 & 1.46 & $0.63-3.37$ & 0.37 & 0.21 \\
\hline \multicolumn{8}{|l|}{ Compensation benefit } \\
\hline$<2,000,000 \mathrm{KRW} / \mathrm{month}$ & 1.00 & & & 1.00 & & & \\
\hline$\geq 2,000,000 \mathrm{KRW} / \mathrm{month}$ & 1.13 & $0.57-2.22$ & 0.72 & 1.52 & $0.98-2.37$ & 0.06 & 0.47 \\
\hline \multicolumn{8}{|l|}{$\begin{array}{l}\text { Injury variables } \\
\text { Pain radiation }\end{array}$} \\
\hline Yes & 1.00 & & & 1.00 & & & \\
\hline No & 2.98 & $1.45-6.12$ & 0.00 & 0.80 & $0.39-1.66$ & 0.55 & 0.01 \\
\hline \multicolumn{8}{|l|}{ Diagnosis } \\
\hline \multirow{4}{*}{$\begin{array}{l}\text { Sprain } \\
\text { Herniated Intervertebral Disc } \\
\text { Disorder }\end{array}$} & 1.00 & & & 1.00 & & & \\
\hline & 0.30 & $0.15-0.58$ & 0.00 & 0.45 & $0.28-0.72$ & 0.00 & 0.19 \\
\hline & & & & & & & \\
\hline & $\mathrm{N}=238$ & Censored $=204$ & & $\mathrm{~N}=167 \mathrm{C}$ & $=77$ & & \\
\hline
\end{tabular}

KRW: Korean Won (1 U.S\$ is equal to about 1,050 KRW in 2005.)

exhibited phase-dependent effects in the univariate analyses, we entered two terms for these variables into the model. One was for their pre-chronic-phase effects and the other was for their chronic-phase effects. The contribution of all other covariates was limited to their combined phase effect. Variables significant in the analysis were age, company size, compensation benefit, pain radiation, and medical diagnosis. One year increase in age was associated with a $5 \%$ reduced recover rate. Workers in companies with below to 1,000 employees showed a 6 times better chance of recover during the pre-chronic phase, and workers without radiating pain showed a $73 \%$ reduced chance of recover in the chronic phase. Workers with HIVD showed $60 \%$ reduced chance to recover than workers with sprain.

Though the difference in the monthly compensation benefit was insignificant in the univariate analysis, it was significant in the Cox regression analysis: workers whose compensation benefit was at least 2,000,000 KRW had a higher hazard ratio than those whose compensation benefit was less.

\section{Discussion}

This study investigated the factors influencing on the duration of work disability after a compensated low-back injury. Significantly reduced chances of recover were found for older age, for workers in companies with $\geq 1,000$ employees, who receiving less than 2,000,000 KRW for compensation benefit, and for workers with HIVD in multivariate analysis.

The predictive ability of age has been found in many previous studies on $\mathrm{LBP}^{11,14-17,19-21)}$, which is due both to the reduced ability of older workers to recover from injuries ${ }^{15,16)}$ and to the reduced likelihood of finding employment once they have recovered ${ }^{16}$. Company size showed the influence on the 
Table 3. Multivariate hazard ratios and $95 \%$ CIs for demographic, work-related, $\&$ injury variables $(n=\mathbf{2 3 8})$

\begin{tabular}{|c|c|c|c|}
\hline Variable & Hazard ratio & $95 \% \mathrm{CI}$ & $P$ \\
\hline \multicolumn{4}{|l|}{ Demographic variables } \\
\hline Age & 0.95 & $0.91-1.00$ & 0.04 \\
\hline Sex Male & 1.00 & & \\
\hline Female & 0.47 & $0.10-2.33$ & 0.36 \\
\hline \multicolumn{4}{|l|}{ Marital status } \\
\hline Single, widow(er), or divorced & 1.00 & & \\
\hline Living as a couple & 1.26 & $0.69-2.28$ & 0.45 \\
\hline \multicolumn{4}{|l|}{$\begin{array}{l}\text { Work-related variables } \\
\text { Company size }\end{array}$} \\
\hline$<1,000$ employees (pre-chronic phase) & 5.92 & $2.53-13.91$ & $<.0001$ \\
\hline$\geq 1,000$ employees & 1.00 & & \\
\hline$<1,000$ employees (chronic phase) & 0.39 & $0.12-1.23$ & 0.11 \\
\hline$\geq 1,000$ employees & 1.00 & & \\
\hline \multicolumn{4}{|l|}{ Length of pre-injury employment } \\
\hline$<10 \mathrm{yr}$ & 1.00 & & \\
\hline$\geq 10 \mathrm{yr}$ & 0.63 & $0.36-1.10$ & 0.10 \\
\hline Union membership Yes & 1.00 & & \\
\hline No & 0.76 & $0.28-2.00$ & 0.57 \\
\hline \multicolumn{4}{|l|}{ Compensation benefit } \\
\hline$<2,000,000 \mathrm{KRW} /$ month & 1.00 & & \\
\hline$\geq 2,000,000 \mathrm{KRW} / \mathrm{month}$ & 1.60 & $1.05-2.42$ & 0.03 \\
\hline \multicolumn{4}{|l|}{$\begin{array}{l}\text { Injury variables } \\
\text { Pain radiation }\end{array}$} \\
\hline Yes (pre-chronic phase) & 1.00 & & \\
\hline No & 1.61 & $0.69-3.75$ & 0.27 \\
\hline Yes (chronic phase) & 1.00 & & \\
\hline No & 0.27 & $0.08-0.85$ & 0.03 \\
\hline Diagnosis Sprain & 1.00 & & \\
\hline Herniated Intervertebral disc & 0.40 & $0.26-0.60$ & $<.0001$ \\
\hline \multicolumn{4}{|l|}{ Chi-square $=59.6381 \mathrm{~N}=238$ Censored $=114$} \\
\hline
\end{tabular}

KRW: Korean Won (1 U.S\$ is equal to about 1,050 KRW in 2005.)

duration of work. Unexpectedly, our analysis revealed that working in a larger company was associated with a decreased probability of recover, which is the opposite result to the previous studies ${ }^{16,17}$. In South Korea, workers in larger companies have a lower probability of dismissal due to injury than those in smaller ones, and it works as an incentive for larger company workers to prolong the duration of work disability.

In the univariate analysis, union member showed decrease chance to recover but this effect reversed in the multivariate analysis. Considering with company size, workers in the small company without union have rare chance to return to the same one ${ }^{22}$. In addition, workers with occupational injury can get compensation benefit during compensated work disability in South Korea. Therefore, they have incentives to prolong duration of compensated disability in order to get compensation benefit.

Workers with radiating pain at baseline showed a reduced chance of recover during the pre-chronic phase. Radiating pain indicates a more widespread injury with possible neural compromise that may contribute to prolonged symptoms and, subsequently, prolonged duration of work disability ${ }^{15)}$. This finding implies that a radiating pain is a risk factor for future back injuries.

Workers with more severe medical diagnosis had a reduced chance of recover compared with workers with less severe medical diagnosis. Hazard ratio obtained in our multivariate analysis is similar to the results of the previous studies which found in their univariate analysis of medical diagnosis as combining the disease phase $\mathrm{e}^{10)}$.

The impact of compensation benefit was significant only in multivariate analysis, and workers receiving more 2,000,000 KRW were less likely to remain in the disability status. Under the workers compensation system, compensation benefit can be increased in proportion to their 
mean daily wage ${ }^{23)}$, and this means that higher income level workers can afford treatments that are not covered by workers compensation to reduce the duration of work disability ${ }^{22)}$.

This article also investigated whether the effects of certain factors vary during different phases of the course of disability. Among demographic, work-related and injury variables, radiating pain and company size showed statistically significant phase-specific effects. The effects of age and union membership, however, did not vary significantly between the phases.

A previous study found that the association between radiating pain and duration of work disability was strongest in the first phase (0-30 d) and negligible for the remainder of the follow-up period ${ }^{15)}$. After 6 months, workers with radiating pain at baseline showed a greater chance to recover in the present study. Although not statistically significant, workers with radiating pain were also associated with a shorter duration of work disability after $180 \mathrm{~d}$ in a previous study ${ }^{15}$. This indicates that radiating pain becomes a "protective" effect in the chronic phase.

Workers working in companies with $<1,000$ employee exhibited a 6 times more chance to recover rate during the first 6 months relative to those working in large companies, and this effect was changed after 6 months to a $61 \%$ disadvantage. The effect differs from that found in previous studies $^{16,17)}$, in which phase specificity was not found. These different results may be attributable to the methods of data collection. The present study did not include workers without post-injury employment and those in small companies because data collection was performed only in companies with a high incidence of musculoskeletal injury. Therefore, this result needs to be confirmed in large-population-based surveys of workers compensation claims.

In conclusion, although the exact cutoff may vary, the results presented here demonstrate the necessity of performing phase-specific analyses to detect possible changes in the strength and direction of associations during the course of work disability. In the policy making related to the workers compensation, especially to reduce the prolonged work disability, this phase-specific approach can be used to develop more appropriate strategy by focusing on the rehabilitation of workers at high risk of chronic disability.

\section{References}

1) Kelsey JL, White AA III (1980) Epidemiology and impact of low back pain. Spine 5, 133-42.

2) Kelsey JL, Golden AL (1988) Occupational and workplace factors associated with low back pain. Occup Med 3, 7-16.

3) Frank JW, Brooker AS, DeMaio SE, Kerr MS, Maetzel A,
Shannon HS, Sullivan TJ, Norman RW, Wells RP (1996) Disability resulting from occupational low back pain. Part II: What do we know about secondary prevention? A review of the scientific evidence on prevention after disability begins. Spine 21, 2918-29.

4) Abenhaim L, Suissa S (1987) Importance and economic burden of occupational back pain: a study of 2,500 cases representative of Quebec. J Occup Med 29, 670-4.

5) Snook $\mathrm{SH}$ (1988) The costs of back pain in industry. Occup Med 3, 1-5.

6) Krause N, Frank JW, Dasinger LK, Sullivan TJ, Sinclair SJ (2001a) Determinants of duration of work-related disability and return-to-work after work-related injury and illness: challenges for future research. Am J Ind Med 40, 464-84.

7) Polatin PB, Gatchel RJ, Barnes J, Mayer H, Arens C, Mayer TG (1989) A psychosociomedical prediction model of response to treatment by chronically disabled workers with low-back pain. Spine 14, 956-61.

8) Krause N, Ragland DR (1994) Occupational disability due to low back pain: a new interdisciplinary classification based on a phase model of disability. Spine 19, 1011-20.

9) Spitzer WO, LeBlanc FE, Dupuis M (1987) Scientific approach to the assessment and management of activityrelated spinal disorders. A monograph for clinicians. Report of the Quebec Task Force on Spinal Disorders. Spine 12, S1-59.

10) Dasinger LK, Krause N, Deegan LJ, Brand RJ, Rudolph L (2000) Physical workplace factors and return to work after compensated low back injury: a disability phase-specific analysis. J Occup Environ Med 42, 323-33.

11) Krause N, Dasinger LK, Deegan LJ, Rudolph L, Brand RJ (2001b) Psychosocial job factors and return-to-work after compensated low back injury: a disability phase-specific analysis. Am J of Indus Med 40, 374-92.

12) Oh JY (2002) Length of disability and cost of low back pain patients from workers' compensation benefit data. Master's thesis, Korea University, South Korea.

13) Paek DM, Lim SH, Han II, Kim DW, Park SB, Lee YK, Lee JS, Lim HJ, Jang YW, Joo YS (2004) Report of medical management associated with work related musculoskeletal disorder in Daewoo Shipbuilding \& Marine Engineering. Wonjin Institute for Occupational and Environmental Health, Seoul.

14) Oleinick A, Gluck JV, Guire K (1996) Factors affecting first return to work following a compensable occupational back injury. Am J Ind Med 30, 540-55.

15) McIntosh G, Frank J, Hogg-Johnson S, Bombardier C, Hall H (2000) Prognostic factors for time receiving workers' compensation benefits in a cohort of patients with low back pain. Spine 25, 147-57.

16) Cheadle A, Franklin G, Wolfhagen C, Savarino J, Liu PY, Salley C, Weaver M (1994) Factors influencing the duration of work-related disability: a population-based study of Washington State workers' compensation. Am J Public Health 84, 190-6. 
17) Infante-Rivard C, Lortie M (1996) Prognostic factors for return to work after a first compensated episode of back pain. Occup Environ Med 53, 488-94.

18) Coste J, Delecoeuillerie G, Cohen de Lara A, Le Parc JM, Paolaggi JB (1994) Clinical course and prognostic factors in acute low back pain: an inception cohort study in primary care practice. BMJ 308, 577-80.

19) Hogg-Johnson S, Frank JW, Rael E (1994) Prognostic risk factor models for low back pain: why they have failed and a new hypotheis. Institute for Work and Health, Toronto, Ontario.

20) Abenheim L, Rossignol M, Gobeille D, Bonvalot $Y$, Fines $\mathrm{P}$, Scott S (1995) The prognostic consequences in the making of the initial medical diagnosis of work-related back injuries. Spine 20, 791-5.

21) Mackenzie E, Morris JA Jr, Jurkovich G, Yasui Y, Cushing BM, Burgess AR, DeLateur BJ, McAndrew MP, Swiontkowski MF (1988) Return to work following injury: the role of economic, social, and work-related factors. Am J Public Health 88, 1630-7.

22) Kim JY (2005) Determinants of duration of work-related disability associated with occupational low back pain. Doctor's thesis, Seoul National University, South Korea.

23) Korea Labor Welfare Corporation (2004) The Industrial Accidents Compensation Insurance Act. http:// www.welco.or.kr/new_english/e_main.asp 